\title{
O Uso de Blogs como Tecnologia Educacional Narrativa para a Forma/Ação Inicial Docente
}

\author{
Blogs as a Narrative Educational Technology for the Pre-Service \\ Educa/Action
}

\author{
Luciane Mulazani dos Santos* \\ Roger Miarka $^{* *}$ \\ Ivanete Zuchi Siple ${ }^{* * *}$
}

\begin{abstract}
Resumo
Este artigo tem como objetivo discutir a utilização de blogs, entendidos como tecnologia da informação e da comunicação narrativa, como um dos instrumentos de avaliação da disciplina de Estágio Curricular Supervisionado do curso de Licenciatura em Matemática de uma universidade pública brasileira. Para isso, apresentamos e discutimos elementos relacionados à escolha do blog como tecnologia educacional narrativa aplicada em processos de avaliação e reflexão da prática docente dos estagiários. Em seguida, a partir da análise dos blogs relativos aos estágios dos alunos participantes da disciplina, articulamos categorias que dizem da experiência docente na formação inicial. Em um próximo movimento, buscamos discutir o uso dos blogs como recurso metodológico, ora como possibilidade de os alunos estagiários se narrarem, ora como possibilidade de narrarem sobre a prática do ser professor. Finalizamos o artigo discutindo este recurso como possibilidade para a formação inicial docente à luz do conceito de forma/ação de Bicudo (2003).
\end{abstract}

Palavras-chave: Blog. Narrativa. Disciplina de Estágio. Formação Inicial. Forma/ação.

\footnotetext{
* Doutora em Educação pela Universidade Federal do Paraná (UFPR). Professora da Universidade do Estado de Santa Catarina (UDESC), Centro de Ciências Tecnológicas, Joinville, SC, Brasil. Endereço para correspondência: UDESC - Departamento de Matemática, Rua Paulo Malschitzki, s/n, Bairro Zona Industrial Norte, CEP: 89219-710,Joinville, SC, Brasil. E-mail: lucianemulazani@gmail.com.

** Doutor em Educação Matemática pela Universidade Estadual Paulista Júlio de Mesquita Filho (UNESP). Professor da Universidade Estadual Paulista Júlio de Mesquita Filho (UNESP), Rio Claro, SP, Brasil. Endereço para correspondência: UNESP - Instituto de Geociências e Ciências Exatas, Avenida 24-A, 1515, Bairro Bela Vista, CEP 13506-900, Rio Claro, SP, Brasil. E-mail: romiarka@gmail.com.

**** Doutora em Engenharia de Produção pela Universidade Federal de Santa Catarina (UFSC). Professora da Universidade do Estado de Santa Catarina (UDESC), Centro de Ciências Tecnológicas, Joinville, SC, Brasil. Endereço para correspondência: Departamento de Matemática - UDESC, Rua Paulo Malschitzki, s/n, Bairro Zona Industrial Norte, CEP: 89219-710, Joinville, SC, Brasil. E-mail: ivazuchi@gmail.com.
} 


\begin{abstract}
The aim of this paper is to discuss the use of blogs, understood as an information and narrative communication technology, as one of the assessment devices of the "Practice in Teaching and Learning Mathematics" course of the Mathematics Program of a Brazilian public university. We present and discuss elements related to the choice of blogs as narrative educational technology applied to processes of assessment and reflection of the teaching practices of pre-service student teachers. After that, taking into consideration the blogs written by the students, we created categories that talk about the students' pre-service teaching experience. We also discuss the use of blogs as a methodological resource, as a possibility for the students to narrate themselves, and as a possibility for them to talk about the practice of the being a teacher. We finish the paper discussing the blogs as pre-service teaching education in light of the concept of Educa/action by Bicudo (2003).
\end{abstract}

Keywords: Blog. Narrative. Practice Course. Pre-service Education. Educa/action.

\title{
1 Introdução
}

A vasta disseminação e utilização de tecnologias de ensino, aprendizagem e comunicação aliada à verificação da ainda frágil integração destas ao contexto educacional são fatores que nos instigam, como educadores e pesquisadores, a buscarmos metodologias de ensino e avaliação que propiciem, no âmbito da Educação Matemática, avanços nos processos de aprendizagem de nossos alunos. Segundo Kaput (1992, apud TALL, 2013), qualquer um que se atreva a descrever os papéis da tecnologia na Educação Matemática enfrenta um desafio semelhante ao de descrever um vulcão em erupção. De acordo com Tall (2013), esta citação de Jim Kaput escrita há mais de duas décadas é hoje tão atual como foi outrora: a tecnologia contemporânea nos apresenta maneiras surpreendentes de operação e comunicação que eram inimagináveis há um tempo não muito distante. Essa celeridade da mudança, ainda de acordo com Tall (2013), é uma das razões da não utilização dos recursos e ferramentas da tecnologia nos processos de ensino e aprendizagem por parte de alguns educadores. Enquanto as crianças e jovens nativos da era digital abraçam a tecnologia de uma maneira orgânica, alguns educadores mostram resistência e dificuldade em fazê-lo, o que impacta, inclusive, em alterações curriculares das disciplinas escolares.

Esta dificuldade não é difícil de diagnosticar. A velocidade de mudança da tecnologia é muito mais rápida do que as possibilidades de mudança curricular que, por sua vez, deve levar em conta as mudanças culturais. Assim, enquanto uma criança pode pegar um iPad com software cuidadosamente projetados para facilidade de uso e descobrir maneiras de usá-lo para benefício pessoal, o responsável pela construção do currículo escolar deve ter tempo para refletir profundamente sobre as questões complexas que surgem na nossa sociedade e sobre a mudança, a longo prazo. (TALL, 2013, p. 2, tradução nossa). 
Em decorrência, mudanças geradas pela inserção das tecnologias de informação e comunicação no nosso cotidiano têm levado educadores de todos os níveis escolares a refletirem criticamente sobre diferentes aspectos dos procesos de ensino, tais como a estrutura curricular, os métodos e ferramentas de avaliação, o planejamento e a execução das aulas, a interação com os alunos e o controle de todas essas atividades. Tomando por premissa o fato que as tecnologias de informação e comunicação têm revolucionado a maneira como as pessoas usam a internet e que tem aumentado o interesse nas potencialidades destas ferramentas nos processos de ensino, apresentamos nesse artigo os resultados de uma pesquisa em que analisamos e discutimos a proposta e a implementação do uso de $\log { }^{1}{ }^{1}$ como diários reflexivos das narrativas de estagiários do curso de Licenciatura em Matemática sobre suas vivências e experiências em atividades de regência em escolas de Ensino Médio.

Entendemos e utilizamos o conceito de narrativa no contexto de definições e análises apresentadas por Freitas e Fiorentini (2007), no que se referem a sua importância como modo de "refletir, relatar e representar a experiência, produzindo sentido ao que somos, fazemos, pensamos, sentimos e dizemos" (p.63) para "tentar dar sentido a uma experiência educativa ou a uma prática social” (p. 65), o que mostra um potencial da utilização das narrativas para compreendermos situações de ensino e aprendizagem no âmbito da Educação Matemática. Complementando essas possibilidades, aparece o fato de que a narrativa pode ser entendida como "modo especial de estudar/investigar a experiência, isto é, como modo especial de interpretar e compreender a experiência humana, levando em consideração a perspectiva e interpretação de seus participantes" (p.63).

Nesse sentido, utilizamos e analisamos o blog como um recurso digital narrativo em que seu autor tem a possibilidade de narrar suas experiências, passando a tomá-lo como tecnologia da informação e da comunicação narrativa. O contexto de sua utilização nos leva à interrogação norteadora da presente discussão: de que forma o blog, entendido como

\footnotetext{
${ }^{1}$ A palavra blog é uma abreviação do termo weblog criado no final dos anos noventa para designar um site no qual um único usuário ou um grupo deles pode facilmente editar e publicar, na internet, artigos sobre determinado tema em comum. Tais artigos - os posts - podem conter diferentes recursos digitais tais como textos, imagens, áudio, vídeo e hyperlinks, aparecendo, geralmente, em ordem cronológica inversa (BOULOS et al., 2006, apud PAPASTERGIOU; GERODIMOS; ANTONIOU, 2011). O surgimento e a diversificação de serviços de criação e hospedagem de blogs, em grande parte gratuitos e de fácil utilização, contribuíram para a sua rápida e crescente disseminação, tornando-os uma forma privilegiada de publicação online nas mais diversas instâncias, inclusive naquelas relacionadas com os processos de ensino e aprendizagem.
} 
tecnologia de informação e comunicação narrativa, pode atuar no processo de acompanhamento e investigação da prática docente do (futuro) professor de Matemática?

Movidos por essa interrogação diretriz e inspirados nas considerações de Freitas e Fiorentini (2007) a respeito das possibilidades da narrativa, traremos, neste artigo, rastros da experiência da utilização de blogs no acompanhamento do estágio de regência de alunos da última fase do curso de Licenciatura em Matemática $^{2}$ e uma discussão sobre suas potencialidades, ao tomá-los como objeto de pesquisa em Educação Matemática. Em especial, buscaremos discutir o uso dos blogs como recurso metodológico, ora como possibilidade de os alunos estagiários se narrarem, ora como possibilidade de narrarem sobre a prática do ser professor. Por fim, buscamos ir além do uso dos blogs, discutindo-os de maneira panorâmica, desprendendo-nos de seus aspectos individuais, à luz do conceito de forma/ação docente de Bicudo (2003).

A disciplina de Estágio Curricular Supervisionado (ECS) é uma instância privilegiada que permite a articulação entre o estudo teórico e os saberes práticos, uma vez que proporciona aos alunos do curso de licenciatura a vivência de processos de ensino e aprendizagem, capacitando-os para o exercício da docência. O fato do professor orientador de estágio utilizar, ao longo dessas atividades, os blogs como elementos inovadores de acompanhamento e avaliação, revela importantes vivências e reflexões da prática docente na formação inicial e insere esses futuros professores em ambientes de ensino e aprendizagem apoiados na tecnologia de informação e comunicação narrativa. No presente estudo, discutiremos a escolha dos blogs como instrumentos de narrativa para acompanhamento e avaliação da disciplina e evidenciaremos a vivência dos estagiários na tarefa de escrita e reflexão de sua prática pedagógica utilizando blogs da internet como suporte, recurso que consideramos especialmente importante por possibilitar ao futuro docente narrar-se, apresentando rastros de suas próprias experiências, compartilhando-as em grupo, desdobrando-se sobre o dito, refletindo. De acordo com Souza (2007),

Do ponto de vista metodológico, a abordagem biográfico-narrativa assume a
complexidade e a dificuldade em atribuir primazia ao sujeito ou à cultura no
processo de construção de sentido. Ao longo de seu percurso pessoal, consciente de
suas idiossincrasias, o indivíduo constrói sua identidade pessoal mobilizando
referentes que estão no coletivo. Mas, ao manipular esses referentes de forma
pessoal e única, constrói subjetividades, também únicas. (p. 65-66)

${ }^{2}$ É importante destacar que o professor da disciplina utilizada para a pesquisa e orientador dos alunos estagiários é um dos autores deste artigo. 
Realizamos a pesquisa a partir da leitura autorizada e da extração de postagens dos blogs criados pelos alunos da disciplina de ECS IV do curso de Licenciatura em Matemática. A partir desses excertos narrativos, analisamos e discutimos a proposta e a implementação dos blogs como (i) instrumentos de avaliação da disciplina por parte do professor orientador; (ii) traços narrativos digitais do registro da vivência dos estagiários como docentes; (iii) ferramenta digital como possibilidade para a formação inicial docente.

Os dados aqui apresentados referentes às postagens dos alunos são extratos selecionados durante a leitura dos blogs por professores orientadores das disciplinas de estágio e são registros fiéis da escrita dos alunos sobre os temas que decidimos abordar, os quais se tornaram nossas categorias de análise. Para cada uma dessas categorias, utilizamos como nome um termo relacionado à Tecnologia de Informação e Comunicação buscando, assim, propor uma integração entre os significados em tal contexto com os significados do registro da vivência dos estagiários.

Nas seções a seguir, são apresentadas as especificidades do blog como instrumento de avaliação no olhar do professor orientador bem como as postagens dos alunos seguidas de discussão que as insere no contexto da utilização das tecnologias de informação e comunicação na educação, em especial, aquelas narrativas.

\section{Conectando o leitor ao contexto do estudo}

Pela estrutura curricular do curso de Licenciatura em Matemática da Universidade do Estado de Santa Catarina, a disciplina ECS IV fecha o ciclo das práticas pedagógicas obrigatórias para a formação acadêmica do futuro professor de Matemática. Nessa disciplina, os estagiários planejam, executam e avaliam aulas de Matemática em nível de Ensino Médio em escolas públicas ou privadas. Sendo uma disciplina semestral com carga horária de 162 horas de aulas práticas, cabe ao professor orientador o acompanhamento dessas atividades e a promoção de reflexão sobre as mesmas. Tais atividades e reflexões são apresentadas pelos alunos no final do semestre em um relatório impresso que reúne também um conjunto de documentos legalmente exigidos pela Universidade como comprovação da realização do estágio.

Do plano de ensino da disciplina de ECS IV para o primeiro semestre de 2012 fizeram 
parte - propostos pelo professor orientador - elementos inovadores de metodologia e de avaliação. São tais elementos, apoiados na Tecnologia de Informação e Comunicação, que nos chamaram a atenção a ponto de realizarmos um trabalho de análise de sua proposta e implementação como instrumento de avaliação dos alunos que cursaram a disciplina. Isso porque, em semestres anteriores, as atividades realizadas foram acompanhadas e avaliadas somente presencialmente e por meio de relatórios impressos. No primeiro semestre de 2012, o professor utilizou também os blogs para registro de narrativas de experiências e vivências no estágio. Na etapa de regência nas escolas concedentes do estágio, momento em que os estagiários ministram aulas de Matemática com conteúdos de Ensino Médio em consonância com o planejamento da disciplina feito pelo professor da escola e respeitando as peculiaridades e condições dos alunos, o professor orientador solicitou aos estagiários que registrassem suas atividades e reflexões no blog. Assim, cada aluno foi responsável pela criação, manutenção e administração do seu blog.

Além de assistir a aulas da regência presencialmente, o professor orientador acompanhou virtualmente as atividades lendo e comentando os blogs. As postagens e comentários assim registrados e compartilhados foram utilizados como um dos instrumentos de avaliação dos alunos. Diferentemente do modelo de avaliação anteriormente adotado na disciplina, desta vez o relatório de estágio impresso não foi a principal atividade desenvolvida pelo aluno já que outras condições, incluindo a construção e administração do blog, também foram acordadas para computar a sua média final na disciplina.

De acordo com o professor orientador, a opção pela inclusão dos blogs como instrumento de avaliação veio como consequência natural da sua vontade de utilizá-los para acompanhar as atividades de estágio dos alunos de uma maneira mais próxima e também consistente com a carga horária da disciplina. Pelas normas internas do estágio, na disciplina de ECS IV o professor orientador deve acompanhar a regência de cada um dos alunos que devem cumprir uma carga horária de 30 aulas. No semestre considerado, a disciplina contou com 9 alunos matriculados, o que tornou inviável ao professor acompanhar presencialmente todas as aulas de regência de todos os estagiários, levando em consideração que as escolas encontravam-se espalhadas em diferentes regiões da cidade e em cidades distintas, que os turnos eram diferentes e que o professor orientador de estágio também desenvolvia outras atividades de ensino e pesquisa na Universidade. A alternativa encontrada pelo professor para 
contornar a impossibilidade de estar presencialmente em todas as aulas de todos os estagiários foi tornar-se presente virtualmente por meio dos blogs. Foi assim que o professor combinou com os alunos que durante a semana assistiria a uma aula de regência de cada um (eventualmente mais de uma) e que os acompanharia sempre pelos blogs, buscando tornar mais próxima e viva a experiência da regência dos estagiários, pois

Quando os registros das atividades de estágio dos alunos são solicitados somente na forma de um relatório final à época da conclusão da disciplina, muitas das informações se perdem por conta da diferença entre o tempo em que ocorre a vivência e o tempo em que ela é registrada. Isso deixa os relatórios finais no papel de "cumpridores de tabela" com registros pró-forma e generalidades vazias. (Professor Orientador, 2012)

Esta constatação decorre da experiência do professor como orientador de estágio dessa disciplina também no semestre anterior à utilização dos blogs. Assim, com a intenção de obter um fluxo contínuo de informações e movimentar reflexões acompanhando semanalmente as experiências vividas pelos estagiários, o professor orientou-os, nessa nova edição da disciplina, a narrarem suas vivências e experiências nos blogs.

Para o professor orientador, foram diferenciadas e inovadoras a proposta e a implementação de atividades da disciplina inseridas em um ambiente digital utilizando os blogs. Nenhum dos professores do curso, até então, incluíram em seus planos de ensino os blogs como instrumento de avaliação. Sendo assim, os alunos ainda não tinham sido submetidos a tal instrumento e critérios de avaliação. Sabendo disso, o professor orientador estabeleceu, no plano de ensino da disciplina, regras bastante claras com relação ao uso da ferramenta e ao conteúdo que deveria ser publicado, bem como os itens que seriam avaliados durante esse processo, como reproduzidas no Quadro 1.

1) Cada aluno deverá criar uma conta individual na base blogger

2) O acesso aos blogs individuais será inicialmente restrito ao professor e aos alunos da disciplina (casos excepcionais podem ser negociados*);

3) Cada aluno deverá postar ao menos uma postagem semanal, contando o fím da semana como meia-noite de quinta-feira;

4) O professor se compromete a ler as postagens dos alunos entre sexta e segunda-feira;

5) O feedback do professor se dará por meio de comentários nos próprios posts.

A avaliação do blog será realizada por meio dos seguintes critérios:

a) respeito à periodicidade semanal de publicações (Peso 2/10);

b) apresentação de rastros de experiências (Peso 2/10);

c) reflexão e desdobramentos do rastro de experiências (Peso 3/10);

d) diálogo com o professor no campo comentários (Peso 1/10).

e) apresentação do blog, em termos imagéticos, inserção de textos, de sons etc. (Peso 2/10)

f) a nota final do blog será quantificada em uma escala de 0 a 10. 
* Algumas exceções com relação à confidencialidade dos blogs foram negociadas com os alunos e por eles autorizadas: a professora e os alunos da disciplina de ECS III para acompanhamento; o professor que assumiria a próxima turma de ECS IV para que continuasse trabalhando com os blogs; e os pesquisadores que trataram de sua análise e escrita do presente artigo.

Quadro 1- Critérios do professor para criação e avaliação dos blogs

Como mostrado acima, cada um dos alunos deveria inserir no blog ao menos uma postagem semanal. O professor orientador usou esta estratégia - considerada por ele como de defesa do blog - para que os alunos não deixassem o blog de lado em momentos em que precisassem, por exemplo, estudar para outras disciplinas. Combinou com os alunos o dia em que leria os blogs - entre sexta-feira e segunda-feira - para que eles não sofressem com a ansiedade de esperar que ele lesse os blogs logo que as postagens fossem inseridas. E, também, para que pudesse se organizar pessoalmente para a leitura, garantindo que nenhuma postagem ficasse sem ser lida e comentada, utilizando o recurso para inserção de comentários disponível nos blogs. Assim, comentou todas as postagens de todos os alunos com observações que envolviam apontamentos e compartilhamento de rastros de experiências, buscando instigar discussões por meio de perguntas diretas.

\section{Estudo de Caso: estagiários conectados}

Ao se buscar nos blogs uma compreensão da reflexão da prática do futuro professor por meio das narrativas, é importante se considerar o contexto no qual tais experiências se efetivam. Atualmente, é indispensável levar em conta as peculiaridades dos processos de ensino e aprendizagem no contexto da cultura digital com seus recursos apoiados nas Tecnologias de Informação e Comunicação, buscando a (re)adaptação do currículo da Licenciatura em Matemática, em coerência com o cenário contemporâneo.

Os desafios de empreender processos de formação inovadores, dentro da perspectiva
de uma sociedade que tem as Tecnologias Digitais da Informação e Comunicação
(TDIC) como elementos mediadores da ação, não são simplórios. Não se trata
apenas de disponibilizar acesso às tecnologias digitais, mas, fundamentalmente, de
se conceber estratégias metodológicas adequadas e que façam valer a
intencionalidade pedagógica e o ganho de aprendizagem dos envolvidos nos
processos (LIMA, 2011, p. 2)

É importante ressaltar que as estratégias metodológicas com o uso de tecnologias digitais não extinguem ou substituem as demais, consideradas tradicionais, e sim as transformam a caminho de uma conexão entre elas. Neste cenário, há uma mudança nos papéis desempenhados por professores e alunos. O professor age como que rompendo as 
barreiras do espaço físico e do tempo transformando sua função de detentor de respostas para aquela de questionador, mediador e aprendiz nas interações, tanto didáticas quanto técnicas. Quanto ao aluno, é fundamental que ele se reconheça como ator nesse cenário com o importante papel de expor seus pontos de vista e reflexões, refletir sobre sua prática buscando aprender com autonomia construindo seu próprio caminhar.

No caso da nossa pesquisa, tratamos de um processo de ensino e aprendizagem apoiado na Tecnologia da Informação e Comunicação questionando sobre como os blogs atuaram neste processo como uma possibilidade de os alunos, futuros professores em processo de formação docente, se narrarem, e o que as narrativas produzidas revelaram sobre a prática do futuro professor.

De forma a responder estas questões, lemos e discutimos as postagens dos blogs criados e administrados por nove alunos da disciplina ECS IV do primeiro semestre de 2012. Para a constituição deste artigo, apresentamos excertos de seis desses nove alunos ${ }^{3}$, representados pelas letras A, D, F, J, M, S. Em consonância com a proposta do professor orientador da disciplina, olhamos para os blogs como instrumentos de narrativa e avaliação da prática pedagógica dos alunos. De nossa parte, refletimos sobre as revelações sobre a prática dos futuros professores presentes em suas narrativas e sobre a inserção desses alunos no ambiente da tecnologia digital educacional. Reconhecemos, assim, as narrativas de alunos do século XXI, que vivem plugados, que navegam por várias janelas ao mesmo tempo, que se comunicam virtualmente: os alunos geração rede que irão se tornar professores no futuro.

\section{Fiz meu login, criei meus inputs, deu bug, tive que fazer reload antes de dar meu} logout: os blogs como instrumentos narrativos de avaliação da prática pedagógica dos alunos

A seguir, apresentamos textos dos estagiários publicados em seus blogs como narrativas de sua entrada, permanência e saída do ambiente de estágio. Reunimos extratos dos blogs que narram rastros de suas experiências e os articulamos em categorias nomeadas segundo termos comumente utilizados no contexto do uso das Tecnologias de Infomação e

\footnotetext{
${ }^{3}$ Durante o processo de confecção deste artigo, enviamos para cada aluno um pedido de autorização para publicação de trechos de seus blogs. Obtivemos, durante esse movimento, autorização de seis desses alunos, de modo que omitimos as informações dos blogs dos três alunos restantes do grupo.
} 
Comunicação para evidenciarmos a vivência desses estagiários na tarefa de escrita e reflexão de sua prática pedagógica utilizando um blog da internet como instrumento narrativo. Além disso, apontamos questões relacionadas com o processo de formação inicial como professores de Matemática.

\section{1 $\operatorname{Login}^{4}$}

As narrativas nos blogs evidenciam rastros de experiência relacionados com os primeiros contatos dos alunos com o novo ambiente de estágio; mostram registros e reflexões relacionados com as expectativas, apreensões, dúvidas e certezas que envolvem o início de um processo tão importante para os alunos em formação que é o momento do estágio de regência. A receptividade nas escolas é um tema bastante discutido pelos alunos ao longo do estágio. Causador de ansiedade, o contato com o novo desperta reflexões dos alunos sobre a forma como a comunidade escolar os receberá no início do processo de estágio, como mostram os relatos a seguir:

Senti o frio na barriga de sempre, mas pude perceber que amadureci bastante em relação à minha segurança defronte a turma. (...) Notei que houve um grande entusiasmo dos estudantes com a presença de uma 'professora nova'em sala. (Blog do aluno $\mathrm{M}, 2012$ )

No início eles não foram muito receptivos, me senti meio 'rejeitada' :( Era como se eu não estivesse na sala de aula. (Blog do aluno D, 2012)

$1^{\circ}$ 8: Nessa turma fui apresentada aos alunos, eles não mostraram nenhuma atitude diferente, achavam normal. (...) 1 19: A professora não gosta muito dessa turma, pois é mais bagunceira e realmente tem alunos que respondem mais, então não me apresentou à turma (porque eu acho que ela não se sentiu a vontade). Os alunos ficaram me olhando, com olhares dizendo: 'quem é essa?' (...) Espero que a turma se acostume comigo, porque sou um 'pouquinho' diferente da professora: eu gosto de escrever no quadro às vezes (quase sempre, exceto no momento do exercício deles), deixo os alunos conversarem um pouquinho, não muito... claro, e vou começar com um jogo, é... estou curiosa para saber a reação deles. (Blog do aluno F, 2012)

É bem possível que os alunos estranhem a mudança de metodologia no início, mas não se deixe abater se algo der errado. Persistência, minha cara, persistência... (Comentário do professor orientador no blog do aluno F, 2012)

\footnotetext{
4 "Código com o qual um usuário se identifica para acessar o servidor de uma rede." (DICWEB, 2013).
} 
As narrativas mostram um misto de confiança e insegurança dos estagiários no início de suas atividades na escola. Mostram, também as expectativas criadas - muitas delas não concretizadas - sobre como se dará o contato inicial com o professor regente e com os alunos das turmas. Refletindo sobre estas questões, podemos perceber como é importante que o professor regente reconheça seu papel na acolhida inicial dos estagiários, pois esse primeiro contato pode determinar a forma como se darão os trabalhos ao longo do estágio.

\subsection{Input In $^{5}$}

Passado o momento de acesso e reconhecimento inicial do ambiente de estágio, as narrativas nos blogs dos estagiários seguem evidenciando estratégias, planejamentos, ações desenvolvidas pelos estagiários na condução de suas regências. Além disso, os registros pessoais de opiniões e concepções mostram como cada um dos autores lida com dúvidas e certezas relacionadas com a prática docente, com a constatação da realidade escolar e com as expectativas sobre o ensino de Matemática, como mostram os relatos que seguem:

Agora, depois de algumas semanas assistindo as aulas, a timidez dos alunos já passou completamente. E a minha também. A maioria deles já conversa comigo e tira algumas dúvidas durante os trabalhos - e até durante as provas (eles tentam né?!) (Blog do aluno D, 2012)

É triste ver alunos de terceiro ano que não sabem que: $V=2 . a^{2}$.Pi.a $\quad=\quad V=2 . a^{3} . P i$. Ou que não conseguem ver um cilindro como rotação de um retângulo. :( (Blog do aluno A, 2012)

Com o passar do tempo de estágio, fui interagindo com os outros professores da escola, me senti acolhida no ambiente escolar, pois os demais professores me tratavam como professora mesmo sabendo que eu era estagiária. (Blog do aluno S, 2012)

A utilização dos blogs é importante para que o professor orientador tenha acesso a rastros das experiências dos alunos, ainda que não esteja fisicamente presente nos momentos em que elas acontecem. Essas narrativas evidenciam reflexões sobre as formas de participação dos estagiários no desempenho de suas atividades de regência, quando tomam contato

\footnotetext{
5 "Designação para a informação enviada para processamenteo em um computador" (DICWEB, 2013).
} 
também com as tensões entre teoria e prática vivenciadas pelos professores na condução de suas aulas:

Nas aulas que eu lecionei eu senti falta de trabalhar com algo que motivasse os alunos, como atividades diferenciadas, por exemplo. Sei que fiz o melhor dentro das minhas limitações, mas sempre me via com planos de aula a serem cumpridos $e$ conteúdos a serem vencidos e percebia que, como os alunos não estavam acostumados com esse ritmo, eles reclamavam que as aulas eram muito pesadas e rápidas. (...) Um defeito grave que sei que tenho que mudar é em relação à autoridade, sei que preciso agir de forma mais rígida e não tão amigável com os alunos, porque isso me prejudica de alguma forma. (Blog do aluno M, 2012)

As narrativas dos estagiários colocam em evidência o famoso par ordenado falta de interesse dos alunos, descontentamento do professor, uma situação relativamente comum para os professores em exercício, mas desconhecida, na prática, pelos estagiários.

Muitas vezes quando estamos dando uma aula tem aquele aluno que não está interessado, que só conversa, atrapalha a aula, fica no celular... Por mais que nos esforcemos para dar uma boa aula, trazer algo novo, não conseguimos atingir TODOS os alunos da sala. Falo por mim, mas talvez alguns de vocês se identifiquem (...).(Blog do aluno D, 2012)

Realmente, D, às vezes dá vontade de baixar a cabeça e sair correndo, por achar que nada do que a gente trabalhou ficou para os alunos, mas calma. (...) Quando vc tiver uma turma regular ficará mais fácil, pois vc terá mais tempo de trabalhar com os alunos de um ponto de vista metodológico, para que eles passem a ver as atividades realizadas em sala de aula como sendo parte de uma articulação maior. (Comentário do professor orientador no blog do aluno $D, 2012)$

Os acadêmicos, em vários momentos em disciplinas do curso de licenciatura, discutem sobre o interesse dos alunos, mas a observação, na prática, dessa situação, os coloca em momento de reflexão sobre a profissão e também sobre a organização escolar, como o caso em que o estagiário estabelece uma comparação entre o ensino em uma escola particular como aquela onde realizou seu estágio - e a escola pública, evidenciando concepções que, $a$ priori, podem influenciar na sua prática docente.

Acredito que a estrutura e a boa organização da coordenação (...) permitem que o professor tenha um cotidiano de trabalho mais digno, quando comparado com a maioria das escolas da rede pública. (...) Ser professor lá não parece ser ruim. (Blog do aluno A, 2012)

Concordo que a situação de professores em escolas particulares muitas vezes é melhor. Convido você, contudo, a pensar não só nas vantagens, mas também nas desvantagens em se trabalhar em uma escola particular. (Comentário do 
professor orientador no blog do aluno A, 2012)

Muitas das concepções dos estagiários são transformadas ao longo da realização do estágio por conta de sua inserção na realidade escolar, o que pode ser visto com o seguinte relato da aluna que narrava, no momento inicial de acolhida no estágio, o seu medo em trabalhar com o Ensino Médio no período noturno:

D: Nas últimas semanas tenho tido mais abertura com os professores. A maioria deles trabalha em mais de um turno nessa escola e costumo ouvi-los reclamar das turmas da manhã, ou da tarde. Da falta de disciplina, do desrespeito... Contudo, dificilmente fazem comentários negativos quanto aos alunos do noturno. Principalmente as professoras, falam que os alunos do noturno são mais maduros, mais afetuosos, e que acabam se apegando a eles. Uma das professoras me falou na quinta-feira (19/04): 'Eles são quase como filhos pra gente...' (Blog do aluno D, 2012)

A narrativa acima, registrada no blog da aluna, evidencia transformações no modo de pensar e de viver a realidade escolar quando o estagiário se integra ao ambiente da escola e passa a enxergar aquele ambiente como os professores que ali atuam como regente das turmas, o que mostra a importância da realização do estágio para o professor que está em formação. Momento importante dessa realidade escolar é aquele em que o estagiário tem a oportunidade de participar das atividades do conselho de classe e vivenciar um momento de reflexão sobre o papel do conselho, situação assim narrada por um dos estagiários em seu blog:

Percebi que o comportamento observado pelos professores sobre os alunos para os quais eu dei aula era o mesmo que eu tinha observado, e as atitudes que foram previstas também condiziam com as que eu tinha em mente. Ponto positivo que encontrei: comprometimento dos professores e da coordenação em resolver os problemas de aprendizagem das turmas. Ponto negativo: falta de tempo para se comentar sobre alunos que não fazem bagunça, ou seja, alunos que sofrem bullying ou tem qualquer outro tipo de problema que não comprometa a turma (os professores apenas dizem: 'ahh esse é quietinho, bonzinho ele. Próximo.' ) (Blog do aluno A, 2012)

A, eu sempre gostei dos Conselhos de Classe, pois são um momento em que há a possibilidade de trabalhar conjuntamente com os professores, sem ter como foco cada uma das disciplinas. Eles têm um caráter mais social, do que disciplinar. Interessante o que você coloca ao final de seu post. Concordo contigo que essas questões se tornam secundárias em um conselho, mas, no entanto, se você as percebê-las e destacá-las na reunião, podem se tornar prioridades. (Comentário do professor orientador no blog do aluno A, 2012) 
Tais observações mostram as percepções desta situação escolar pelo aluno como tendo um caráter mais social do que disciplinar, como sendo um dos momentos em que professores e coordenadores trabalham conjuntamente desfocando um pouco de cada uma das disciplinas individualmente. Ainda que elogie o comprometimento dos professores, o estagiário relata perceber que muitos assuntos não são tratados, nesse momento, como deveriam, muito provavelmente devido à relação entre tempo e prioriades. Além disso, evidencia uma sintonia entre uma percepção pessoal sobre a turma com a qual trabalhou e as considerações apresentadas pelos professores da escola durante o conselho de classe.

\subsection{Bug $^{6}$}

Momentos entendidos pelos estagiários como frustrantes ou malsucedidos também são postos em discussão pelos estagiários em seus blogs por meio das narrativas das situações em que ocorrem, quando expressam suas opiniões sobre a realidade escolar e as tensões entre teoria e prática, como mostrado nos relatos a seguir:

Me sinto frustrada quando me dedico para fazer algo novo, diferente e o aluno simplesmente não se interessa, ou vai muito mal numa prova. (Blog do aluno D, 2012)

Nas aulas que eu lecionei hoje percebi CLARA e NITIDAMENTE que os alunos funcionam como máquinas adolescentes: eles só sabem resolver exercícios que seguem a mesma linha de raciocínio que os anteriores. Se é alterado uma vírgula, PRONTO, o mundo caiu e eles nem tentam, só afirmam que NÃO SABEM ou que a professora não ensinou! Isso me chateia sabe? Porque estamos formando seres pensantes e nosso objetivo como professores é que eles aprendam de fato e não que saibam reproduzir mil vezes um mesmo exercício. Só acho que esse não é o caminho para um aprendizado efetivo e está bem longe de ser! (...)Não quero que meus alunos tenham esse comportamento, aliás, nenhum aluno deveria ter, não é? (Blog do aluno M, 2012)

M, entendo bem o que diz e sei que isso acontece com MUITA frequência. Talvez no estágio você não tenha tempo para mudar essa característica dos alunos, mas quando vc tiver sua sala, tenho certeza que vc conseguirá trabalhar essa característica dos alunos. (Comentário do professor orientador no blog do aluno M, 2012)

\footnotetext{
6 "Erro na lógica de um programa que o impede de funcionar corretamente." (DICWEB, 2013)
} 
O comentário importante que tenho para essa semana é que estou perdendo autonomia nessa fase final da regência. Dá pra ver que eu tô um pouco revoltado (risos), mas isso é efeito de muitas coisas que aconteceram essa semana. (Blog do aluno A, 2012)

A, entendo bem o que sente. Também já tive problemas em sala de ter que abdicar de um pouco de minha autonomia por conta de ordens 'vindas de cima'. Em escolas particulares isso é bastante comum. Eu sei que está fazendo o seu melhor. Tem horas que a gente tem que ceder um pouco. O importante é não desanimar e tirar isso também como aprendizado. Afinal, lidar com atitudes e indicações com que não se concorda também faz parte da profissão docente. A parte boa é que quando você tiver sua turma o grau de liberdade de trabalho tende a ser maior. (Comentário do professor orientador no blog do aluno A, 2012)

Percebe-se o descontentamento do estagiário com a rotina do estágio, com o que ele chama de autonomia, ou seja, com a liberdade de trabalho quando a regência se encaminha para seu final. Mostra, ao estagiário, uma outra realidade da sala de aula, quando o professor precisa se adequar a recomendações e ordens recebidas quanto ao conteúdo, ao currículo, a prazos e cronogramas. É uma observação relacionada à liberdade de trabalho do professor. Nesse caso, sendo estagiário, isso fica mais marcante; quando for efetivamente regente da turma, isso tende a diminuir. Isso mostra o tipo de comportamento de alunos estagiários que pensam que vão chegar à escola e dominar a situação escolar sem interferência do professor regente ou da coordenação.

Uma situação recorrente nos estágios, já percebida pelos professores orientadores de estágio em outras oportunidades são os comentários dos professores das escolas relacionados à profissão que, na maioria das vezes, servem de desestímulo aos estagiários. Na turma em que analisamos os blogs, mais uma vez surgiu essa situação, representada pelo seguinte relato:

Cerca de 5 professores (...) vieram conversar comigo (em diferentes momentos do meu estágio e de diferentes maneiras) para me dar um conselho. Abre aspas: "Desista enquanto há tempo." Fecha aspas. Sim, desista de ser professor. Eu fiquei bem preocupado com a seriedade com que alguns davam esse conselho. Era como se lecionar fosse o maior pesadelo do mundo! Tá certo que a vida de professor não é fácil, e que o salário é baixo e tudo mais... Mas desincentivar alguém a ser professor é pegar pesado. O pior é que eu tive aula com esses professores e eu sei que eles são ótimos, eu os admiro! Engraçado é que quando eu dizia que iria seguir a carreira acadêmica, e tentar o mestrado, e que o meu objetivo era trabalhar em universidade, eles olhavam meio desconfiados como se isso não fosse uma coisa possível(Blog do aluno A, 2012). 
Entendo bem o que você tem passado ao receber esses comentários de seus professores. Eu também já passei por coisa similar. Tive uma grande pressão durante a faculdade para seguir carreira na Matemática Pura. Te digo que nunca se sabe até onde conseguiremos chegar sem antes tentar. Defina suas metas e, com o devido suor, não tenho dúvidas que você vai longe. (Comentário do professor orientador no blog do aluno A, 2012)

Por si só, a regência de estágio é uma condição que traz ansiedade e apreensão para os futuros professores. Quando eles se deparam com situações em que percebem os professores em exercício falando mal da profissão e da situação escolar, acabam por questionar a si mesmos sobre suas pretensões com relação à profissão de professor. Percebemos que essa sitauação traz desconforto e indignação aos nossos alunos, que se mostram reflexivos quanto à postura profissional de futuros colegas e ao futuro da profissão de professor.

\section{4 $\operatorname{Reload}^{7}$}

Os movimentos de reflexão sobre mudanças de concepções e revisões de estratégias no decorrer da prática do estágio chegam ao professor orientador por meio de narrativas registradas nos blogs que permitem discussões relacionadas entre o planejamento idealizado e a realidade escolar encontrada pelos estagiários, como evidenciam as narrativas a seguir:

(...) no processo de ensino-aprendizagem é preciso de mais do que só um professor dedicado... (Blog do aluno D, 2012)

(...) 'pequenas' coisas que percebemos que atrapalham no desenvolvimento das aulas são um alerta para tomarmos cuidado quando nós formos os professores. Pois os alunos percebem nos detalhes o quanto um professor está comprometido com a turma... (Blog do aluno D, 2012)

$D$, concordo com vc. Essas pequenas coisas nos dizem muito sobre a prática do professor. (Comentário do professor orientador no blog do aluno D, 2012)

Mudei de opinião: prefiro os meus pestinhas do semestre passado. HAHAHA. Pois é. Acho que eu lido muito melhor com o fundamental do que com o médio, mas acredito que isso seja porque eu tenho cara de que estou no ensino médio (risos), daí não consigo passar uma imagem de autoridade. Tenho que chamar a atenção da turma o tempo todo e assim acabo passando por um professor chato... (Blog do aluno A, 2012)

\footnotetext{
7 "Recurso dos programas de navegação pela Internet que, quando acionado, recarrega a página Web que está sendo exibida no momento." (DICWEB, 2013)
} 
Eu tinha reformulado todo o meu planejamento, para tentar dar uma aula menos tradicional. (Blog do aluno A, 2012)

Pude ver claramente que a turma é um reflexo do professor seja nas atitudes, seja na postura, em tudo. É o professor que faz uma aula ser animada ou não, ser entediante ou não, ser eficiente ou não. Pude comprovar isso no decorrer dessa semana. (Blog do aluno M, 2012)

Eu tinha duas turmas de terceiro ano para lecionar o mesmo conteúdo, e tinha pensado em fazer o mesmo planejamento. Depois de conversar com o professor (logo após ele ver a minha primeira aula) decidi bolar outro planejamento para o outro terceiro ano. (Blog do aluno A, 2012)

Gostei da inversão e mais ainda do motivo para ela. Você ainda não tinha me falado que uma das razões era por volume não trabalhar com a geratriz. Ponto pra vc. Mostra reflexão sobre a prática. (Comentário do professor orientador no blog do aluno A, 2012)

Apesar de ter dado a aula de forma bem mais tranquila, não senti que os alunos estavam envolvidos nas atividades. Talvez tenha sido porque eu falei demais (risos), ou porque era segunda-feira 7:30, ou porque eu ainda não tinha intimidade com a turma, ou de tudo um pouco. (Blog do aluno A, 2012)

Quanto ao envolvimento, é tanta coisa que influencia. Nada garante que o pessoal vai cair de cabeça na atividade. Quando vc for o professor oficial da sala, vai ter mais tempo para conhecer a turma e ver o que a atinge. (Comentário do professor orientador no blog do aluno A, 2012)

Sobre essas questões, os estagiários narram experiências e vivências que mostram suas reflexões sobre a prática docente.

\subsection{Logout $^{8}$}

As conclusões acerca da realização do estágio, quando do encerramento das atividades, também são narradas nos blogs, mostrando como cada um dos estagiários observa a sua própria prática e a sua inserção no ambiente escolar, evidenciando reflexões sobre a realidade escolar, a postura do professor e as expectativas para a profissão:

Percebi que agora ao final das aulas de regência as turmas já estavam se adaptando a minha forma de trabalhar e de conduzir as aulas. E eu também já estava conseguindo acompanhar melhor o ritmo deles e me impor mais. Realmente, acredito que quando a turma for 'minha', a sincronia vai ter tempo pra ser construída e a

\footnotetext{
8 "Processo de encerramento de uma seção em uma rede de comunicação após o log off [comando de desconexão em uma rede de comunicação]." (DISCWEB, 2013)
} 
metodologia não vai ser mais uma dificuldade tão grande para os alunos... nem para mim. (Blog do aluno D, 2012)

Bom gente, terminou o período de regência. Mas, esse é só o fim de uma das muitas temporadas que virão... Foi uma experiência de muito aprendizado, crescimento, amadurecimento. Foi repleta de emoções, decepções, frustrações, alegrias... No final dessa temporada percebo o quanto ainda tenho a aprender com toda essa experiência. (Blog do aluno D, 2012)

A: Eu esperava mais, em muitos aspectos. Esperava que eu seria mais paciente quando deveria ser, esperava cativar mais os alunos e esperava tornar as aulas mais dinâmicas. Faltou tempo para me acostumar com as turmas e aprender a lidar com elas, afinal é um estágio de apenas 1 mês. Faltou empenho também de minha parte em tentar fugir da aula tradicional. Eu esperava mais dos alunos também, mas acredito que isso não é uma coisa a qual podemos nos dar ao luxo, rs. (Blog do aluno A, 2012)

Infelizmente (ou felizmente), ao final do período de regência eu percebi que não gostarei de lecionar futuramente para as turmas do Ensino Médio, porque lidando com eles eu percebi que não consegui dar o meu melhor nas aulas, por mais que eu tentasse, porque as turmas não me motivavam como aconteceu no estágio passado no Ensino Fundamental. Como é uma postagem de despedida, do ÚLTIMO estágio, sente-se certa nostalgia. E pensar que quando eu cursei o primeiro estágio eu já tinha pesadelos envolvendo o dia em que eu de fato teria que encarar uma turma cheia de aluninhos... pronto, passou e nem doeu tanto assim! (Blog do aluno M, 2012)

M, o Ensino Médio oferece suas próprias dificuldades. Cativar e motivar os alunos às vezes é mais complicado. Leva algum tempo que vocês não dispõem no estágio. Quando você tiver suas turmas, garanto que poderá lidar com isso com mais calma, de modo a você também se motivar mais. (Comentário do professor orientador no blog do aluno M, 2012)

Ao final da prova eu pedi que quem se sentisse a vontade, poderia comentar ou sugerir algo sobre as aulas que eu administrei na turma deles, deixando bem claro que isso não iria interferir de maneira alguma na nota. Li comentários sinceros e um fato interessante foi que eles só confirmaram o que eu já tinha avaliado a meu respeito. Achei importante ouvir as críticas deles, que com certeza vão contribuir muito na minha formação. Dá medo, mas isso contribuiu muito para o meu aprendizado.(...) De forma geral, concordei com as críticas feitas a meu respeito $e$ percebi que de fato elas foram um reflexo das minhas aulas. Tenho muito a evoluir ainda e creio que essa experiência me ajudou a compreender as falhas e o que deve ser mantido. (Blog do aluno M, 2012)

Achei ótimo sua abertura a escutar os alunos sobre suas aulas. Poucas pessoas têm peito para isso. Dá um medo danado de escutar críticas...rs. Ponto positivo pra vc. (Comentário do professor orientador no blog do aluno M, 2012) 
Dá medo sim, mas isso contribuiu muito para o meu aprendizado.(...) De forma geral, concordei com as críticas feitas a meu respeito e percebi que de fato elas foram um reflexo das minhas aulas. Tenho muito a evoluir ainda e creio que essa experiência me ajudou a compreender as falhas e o que deve ser mantido. (Blog do aluno $\mathrm{M}$, 2012)

A narrativa acima evidencia uma pré-disposição da estagiária em ouvir críticas a respeito da sua prática no estágio advindas dos alunos com quem trabalhou. Iniciativa não muito comum, nem todos os alunos narraram situaçãoes em que se dispuseram a ouvir as impressões dos alunos sobre a prática do estágio.

\section{Narrativas do tipo Meu querido diário: a inserção dos alunos no ambiente da tecnologia digital educacional}

Com a finalização da disciplina e, por conseguinte, do uso dos blogs, buscamos realizar um movimento de nova dobra sobre os blogs, agora com o objetivo de compreender modos como os alunos vivenciaram esse recurso metodológico. Para isso, lançamos mão das próprias postagens realizadas pelos alunos em seus blogs e de relatos narrativos que tinham elaborado por ocasião da escrita de seu relatório final. Tais textos, articulados, produziram a categoria ora apresentada e evidenciam a forma como os estagiários compreenderam o papel dos blogs no registro de suas narrativas sobre as atividades realizadas no estágio.

O blog se tornou um meio de expressão mais livre do que o relatório de estágio, tal como apresenta a narrativa:

D: Acho que o objetivo do estágio não é ficar encontrando os defeitos da escola e do professor e "jogar tudo no ventilador". E, de fato, se eu estivesse escrevendo o relatório, não mencionaria muitas coisas, ou tomaria mais cuidado na escolha das palavras. (Blog do aluno D, 2012)

As narrativas evidenciam a resistência inicial do estagiário com relação ao uso do blog e a posterior constatação da sua utilidade como meio de registro de narrativas pessoais sobre as experiências vividas utilizadas tanto para reflexão quanto para a escrita do relatório final de estágio, tais como se apresenta na narrativa:

Num primeiro momento, não gostei nem um pouco da ideia de ter que escrever um blog. O primeiro pensamento que tive foi: "que saco, mais um professor de educação querendo inventar moda só pra me dar trabalho". Acontece que, com o tempo, percebi que além de muito útil, foi divertido escrever o blog. Além dele aumentar a relação professor/aluno/colegas, a ideia de usar uma linguagem informal facilitava a 
análise que devíamos fazer com relação ao estágio. A obrigatoriedade de postagens semanais permitia que o acompanhamento que o professor tivesse fosse constante $e$ presente, mesmo que a distância. A escrita do relatório final também ficou facilitada, pois bastava acessar o histórico do blog para lembrar o que aconteceu no início do semestre. Enfim, no final das contas, acabei achando a ideia do blog super válida, desde que ele seja acompanhado de perto pelo professor e a avaliação qualitativa $e$ quantitativa das postagens seja rigorosa (como aconteceu na disciplina de estágio) (Blog do aluno A, 2012)

A importância do uso ágil dos blogs para narrativa e discussão de situações vivenciadas nos estágios, utilizando o blog como um canal de comunicação direta com o professor orientador e com os colegas de turma, como evidenciam as narrativas:

Preciso dividir com vocês a minha revolta de hoje, poderia deixar para postar na quinta-feira, quando eu faria um resumo das aulas da semana, mas, a meu ver, isso é muito grave para esperar(Blog do aluno M, 2012).

Em relação ao blog, julgo que é uma ótima ferramenta para nós, estagiários, expormos as nossas angústias e expectativas de uma maneira informal e acredito que o fato de eu escrever o que estava acontecendo durante as semanas de estágio, muito contribuiu para que eu refletisse sobre os acontecimentos posteriormente. E é nisso que o nosso aprendizado se baseia, em reflexões. (...) Quando eu for professora há тииииииииииito teтро, quero ler esse blog de novo e relembrar de tudo o que eu senti durante a realização desse estágio e será muito divertido, posso garantir. (Blog do aluno M, 2012)

No início do estágio, o professor informou que cada licenciando matriculado na disciplina de estágio deveria criar um blog para ser atualizado semanalmente com o que cada um acreditasse ser pertinente a seu estágio. Estes Blogs eram fechados, podendo ser aberto apenas para os alunos e orientadores das disciplinas de estágio III e IV. Seguindo a orientação do orientador criei um blog intitulado "Experimentos na escola", no qual pretendia cumprir o proposto, pois inicialmente achei a ideia interessante. Porém não me senti muito confortável com a exposição no blog, falhando muitas vezes na periodicidade das postagens, não conseguindo cumprir esta parte do combinado satisfatoriamente. (Blog do aluno S, 2012)

S, suas postagens são ÓTIMAS! Creio que você se sentia um pouco insegura em deixar o blog fluir. Tenho certeza absoluta que capacidade você tem. (Comentário do professor orientador no blog do aluno S, 2012)

\section{0 que as narrativas produzidas revelam sobre a prática do (futuro) professor}

Como próximo movimento, desdobramo-nos sobre as narrativas dos estagiários buscando avaliar as potencialidades que a tecnologia educacional narrativa utilizada revela 
sobre a prática do (futuro) professor. Percebemos que os blogs permitiram que rastros de tensão pudessem ser registrados, o que não ocorria até então na formalização do relatório final. Os afetos e desafetos, dificuldades, medos, expectativas etc. ganharam espaço nos relatos. Faziam parte dos blogs como atores principais e não coadjuvantes. A formação desses estagiários pôde ser registrada de maneira processual. A possibilidade de revisitar postagens mais antigas permitiu-lhes acompanhar o próprio movimento de formação. Com atenção, perceberam sinais de amadurecimento, refletiram sobre atitudes que gostariam de mudar. Mais que isso, perceberam-se como professores cujas ações desencadeam reações no ambiente educacional.

Uma das linhas de tensão apresentadas e que dá título a esta seção diz da presença do estagiário na escola. Para a universidade, o estagiário é considerado futuro professor e na escola, ao reger uma turma, necessita afirmar sua autoridade. Para seus alunos, não é aprendiz, mas professor. Como professor, necessita cativar sua turma, tem suas preferências. Como professor, tem dificuldades. Como professor, experimenta. Como professor, acerta e erra. Além disso, como professores regentes, revelaram dificuldades encontradas ao dividirem o espaço da sala de aula com os alunos e outro professor - oficial da turma -, relações estas que nem sempre se mostraram amigáveis. Sentiram a presença dos outros, suas diferenças e similaridades. Buscaram compreendê-los, apresentando movimentos de abertura ao outro.

As narrativas revelaram como este estagiário-professor se relaciona com os diferentes atores sociais da escola. A escola deixou de se resumir à sala de aula, ampliando o seu espectro de relações. Coordenação e outros professores se destacam na vivência dos professores-estagiários, por vezes ajudando-os, por vezes desmotivando-os. Ao registrarem suas vivências, analisam criticamente a prática desses atores sociais da escola, indicando necessidades locais, como a de um olhar mais focado para determinados alunos, que passam desapercebidos. As narrativas mostraram uma temporalidade própria, em que passado, presente e futuro se imbricam. As experiências dos estragiários trouxeram à tona experiências passadas significativas e expectativas futuras. Ao narrarem-se, lançam-se ao futuro em possibilidades, que ganham significado com suas experiências. Tal expectativa veio recorrentemente acompanhada de medo e frustração nas narrativas; medo do incerto em uma profissão a que se embranhavam; frustração ao sentirem que não atendiam as próprias expectativas. Consideramos, no entanto, que a presença de tais sensações nas narrativas seja 
bastante positiva, por poderem ser interpretadas como um respeito à profissão que os estagiários escolheram e um indício de que a tomam com seriedade. No que se refere à interação entre os diferentes estagiários por meio de seus blogs, ao ler os relatos de seus companheiros, os estagiários demostraram a possibilidade de confrontarem-se com diferentes realidades. De algum modo, a experiência de seus companheiros passa a fazer sentido para eles mesmos, ampliando suas próprias vivências e promovendo a emissão de posicionamentos justificados. Por outro lado, percebemos pelos relatos que alguns alunos não se sentiram à vontade com a exposição de reflexões e ideias via blog. Tal incômodo se mostrou de diferentes maneiras: por compartilhar com um grupo grande ideias muitas vezes íntimas; por receio de não ter suas postagens populares; e por temer que o orientador da disciplina não apreciasse suas narrativas. Uma possibilidade que se mostra para a utilização dos blogs de modo a diminuir essa sensação de exposição é aquela em que os estagiários têm a liberdade de escolher seus leitores, a quem autorizariam a leitura.

No que se refere aos comentários do professor orientador, percebemos que este buscou mobilizar os alunos a irem além de suas descrições. Suas inserções ora visavam a uma reflexão ou aprofundamento, ora motivavam, ora afagavam à moda de um ombro amigo. Além disso, incentivava, na medida do possível, que os estagiários buscassem por aquilo que possivelmente escapasse durante as atividades na escola. Desse modo, consideramos que sua presença nos blogs foi essencial para manter seu movimento. Ao buscar promover reflexões, o professor orientador atentou-se aos desdobramentos dos fatos descritos e às discussões que envolviam opiniões sobre Educação, Educação Matemática, prática docente etc., de modo que o ato reflexivo pudesse deslocar aquelas primeiras opiniões em direção a uma compreensão refletida.

\section{Do loop $^{9}$ à interpretação do uso dos blogs como possibilidades de forma/ação}

Como movimento final apresentado neste artigo, buscamos transcender às manifestações individuais dos $b \log s$, sintetizando as interpretações das narrativas dos estagiários, o discurso do professor orientador e a análise dos pesquisadores, expondo

\footnotetext{
9 " Num programa de computador, série de instruções na qual, a partir de certo ponto, volta-se ao ponto inicial da série, e assim indefinidamente ou até que se verifique determinada situação programada." (AULETE, 2013)
} 
possibilidades de forma/ação inicial de professores.

Para isso, ressaltamos as partículas constituidoras da palavra formação para "enfatizar o significado de forma, como formato ou aparição de algo que toma forma por meio de um ato atualizador, o qual lhe serve como conteúdo e força que impele à forma apresentada".

No caso da formação do professor de matemática, essa forma/ação ocorre no próprio ato de efetuar a educação informadora e formadora. Com essa concepção fenomenológica de forma/ação, o foco passa a ser o movimento constante de pensar e repensar a ação, em um movimento de ação-reflexão-ação-reflexão do professor, por entendermos que o profissional nunca está formado, mas sempre em processo de forma/ação. (MIARKA; BICUDO, 2010)

Percebemos que os $b \log s$, por suas próprias características narrativas, permitiu a realização da dinâmica conforme intencionada pelo professor orientador, trazendo à tona rastros de experiência dos alunos, que puderam ser problematizados e desdobrados em novas discussões.

Seu uso propiciou uma educação condizente com um ideal de forma/ação, na medida em que, respeitando o movimento subjetivo de cada aluno, possibilitou movimentos individuais de ação e reflexão, desdobrados individualmente, pelos próprios alunos que se narravam, ou coletivamente, quando discutidos por outros alunos. Coletivamente aquelas experiências narradas se lançavam em tentáculos, ampliando seu alcance.

A não imposição de um estilo aos blogueiros trouxe liberdade de escrita, incentivando a criação de elementos próprios da personalidade de cada um dos alunos, de modo que a tarefa formativa priorizou a multiplicidade de vivências do professorado - palavra entendida como modos de exercer a docência - ao invés de buscar por um cânone formativo.

As narrativas, assim, possibilitaram a emergência de elementos que caracterizassem a criatividade do aluno e sua preocupação com os leitores com a inserção de cores, textos, sons, vídeos etc.

A respeito da forma escrita, ao não estabelecer regras a priori em termos da coerência com as normas cultas da língua portuguesa, o professor orientador possibilitou aos alunos que transitassem de modo narrativamente livre pelo espaço dos blogs, caracterizando sua personalidade e mostrando a fluidez de suas ideias na escrita.

Dessa perspectiva, podemos tomar nesse processo de forma/ação cada um dos atores desse grande palco educacional como participante de "uma viagem na qual cada um venha a ser o que é, [e] o mestre [orientador] da leitura [e da escrita] é um estimulador para a viagem" 
(LARROSA, 2005, p. 45-46).

\section{Referências}

AULETE. iDicionário Aulete. Disponível em: <http://aulete.uol.com.br/loop>. Acesso em: 20 abr. 2013.

BICUDO, M. A. V. Formação do professor: um olhar fenomenológico. In: BICUDO, M. A. (Org.). Formação de professores? Da incerteza à compreensão. Bauru: EDUSC, 2003. p. 7-46.

DICWEB. Dicionário de Informática. Disponível em < http://www.dicweb.com>. Acesso em: 20 abr. 2013.

FREITAS, M. T. M.; FIORENTINI, D. As possibilidades formativas e investigativas da narrativa em educação matemática. Horizontes, São Francisco, v. 25, n. 1, p. 63-71, jan./jun., 2007.

LIMA, M. R. Blog como Recurso Didático: instrumentação e reconfiguração da prática docente na cibercultura. Revista Tecnologias na Educação, Minas Gerais. v. 3, n. 1, p.1-15, 2011.

LARROSA, J. Nietzsche \& a Educação. Belo Horizonte: Autêntica, 2005.

MIARKA, R.; BICUDO, M. A. V. Formatação do Professor de Matemática e suas Concepções de Mundo e de Conhecimento. Ciência \& Educação, Bauru. v.16, n. 3, p. 557-565, nov. 2010.

PAPASTERGIOU, M.; GERODIMOS, V.; ANTONIOU, P. Multimedia Blogging in Physical Education: effects on student knowledge and ICT self-efficacy. Computer \& Education, Maryland Heights, EUA,v. 57, n. 3, p.1998-2010, 2011.

SOUZA, E. C. (Auto)biografia, histórias de vida e práticas de formação. In: NASCIMENTO, A. D.; HETKOWSKI, T. M. (Org.). Memória e formação de professores. Salvador: Edufba, 2007. p. 5974.

TALL, D. The Evolution of Technology and the Mathematics of Change and Variation. In: ROSCHELLE, J.; HEGEDUS; S. (Eds). The Simcalc Vision and Contributions: Democratizing Access to Important Mathematics. Dordrecht: Springer, 2013. p. 449-561. 